Piyasiri and Ariyawardana. 2002. Sri Lankan Journal of Agricultural Economics. Volume 4. Part 1. Pp.107-119.

\title{
Market Potentials and Willingness to Pay for Selected Organic Vegetables in Kandy
}

\author{
A.G.S.A. Piyasiri and A. Ariyawardana*
}

\begin{abstract}
Organic products are considered to be superior in quality compared to conventionally produced products, since it has been proved that organic products help prevent several health hazards. Therefore, demand for organic products are increasing all over the world, as well as in Sri Lanka. Given this increasing demand for organic products, this study was conducted with a view to identifing the market potentials for organic products and consumer expectations in Kandy. Further, it identifies the factors that influence the additional willingness to pay for organic vegetables. The research was conducted in three supermarkets, namely, Cargills, Dhanasiri and Royal Garden Mall. Thirty respondents were randomly selected from each of the supermarkets.

Results reveal that most of the consumers are aware of organic products and this awareness has influenced their consumption of organic products in the past. Further, a majority of the consumers considered price as an important factor for their organic product consumption and have attached a higher importance for certification from a reputed organization. Consumers also indicated that organic products should be sold in easily accessible shops for the convenience of purchasing. Results of the regression analysis revealed that of the socio-demographic factors, income, environmental education and years of education significantly influence the willingness to pay for organic vegetables. Based on the study it could be concluded that consumer awareness effectively advances the demand for organic products and there is a high potential to introduce organic products to the supermarkets in Kandy. Therefore, along with introducing organic products, marketers should also direct proper awareness programs among consumers in promoting the demand for organic products.
\end{abstract}

The authors are, respectively, Final Year Undergraduate Student at the time the study was conducted, and Senior Lecturer in Agricultural Economics, University of Peradeniya. 


\section{Introduction}

Organic products can simply be identified as the products that come from organic production processes or from organic farming. The United States Department of Agriculture defines organic production as a production system, which avoids or largely excludes the use of synthetically compounded fertilizers, pesticides, growth regulators and livestock feed additives to the maximum extent feasible, or farming systems that rely on crop rotation, residues, animal manure, legumes, green manure, off-farm organic wastes, and the aspects of biological pest control measures, soil productivity and tilth, to supply plant nutrients and to control insects, weeds and other pests (Alvares et al., 1999).

Given today's extensive use of pesticides, it is almost impossible for any one to avoid daily exposure to low levels of several different pesticide residues. Researchers have found that there are possible adverse effects on human health arising from continuous long-term, low-level pesticide exposure or chronic exposure. The London Food Commission conducted a toxicological survey on active ingredients currently permitted for use by the United Kingdom pesticide manufactures. Result of the survey showed that of the 426 chemicals listed, 68 to be carcinogenic, 61 to be mutagenic and 35 to have various reproductive effects, ranging from impotency to a variety of birth defects. In total, 40 per cent of the pesticides currently in use were linked with at least one adverse effect (Agrochemical, 2001).

Traditional agricultural practices in Sri Lanka have most of the significant features and ingredients of present day organic farming, indicated by the above definition and the International Foundation of Organic Agriculture Movement's (IFORM) basic standards in the United Kingdom. In Sri Lanka, organic farming practices with proper standards were initiated in 1979 by a non government organization, namely, "Gami Seva Sevana" (Jayakody, 2001). By 1999, there were 172 farmers, who were practicing organic farming in Sri Lanka. Their cultivation covered over 550 ha of land, which was 0.02 per cent of the total agricultural land in the country (FAO Statistical Database, 2001). These organic producers mainly target to produce organic vegetables, spices, fruits and eggs for the local market in small quantities and organic tea in large quantities for the international market. 
Since consumption of organic food products is the best remedy to prevent the numerous health hazards caused by conventionally produced food products, the global market has experienced exceptionally high growth in organic foods. Especially, demand for organic food products in the United States, Europe, and in other countries is growing rapidly, yet market shares remain quite small. The Organic Monitor estimated that the international market for organic food reached US \$ 26 billion in the past year 2001 (Organic Monitor, 2001). However, in Sri Lanka, the market for organic products is not well developed and no market statistics are available. It is characterized by lack of proper retail venues, lack of continuous supply, lack of certification, poor quality products etc. Further, none of the marketers have adopted successful marketing strategies for the sustenance of the organic market in the country. But, there is a growing trend among urban consumers to try organic products from places where they could get an assurance about the quality of the products, as they do not get any chance to consume pesticide free food products (Anuradha, 2001).

Further, market features of organic products in Sri Lanka show that it is still in the "introduction stage" of the product life cycle. To achieve a higher degree of market share, organic marketers should introduce their products to a correct target group adopting proper marketing strategies. In this introduction process, identification of market potentials of organic products is important, since the product attributes are not familiar to consumers. Consumer awareness and experiences about organic products could determine the demand for these organic products. Furthermore, market potentials are mainly determined by consumer expectations of the product attributes, which are attached to the product such as price, quality, certification etc. (Kotler, 2001). Therefore, producers must identify such qualities and their level of importance in adapting successful promotion campaigns.

Given this background, this study was conducted with the general objective of identifying the market potentials and consumer expectations of organic products in Kandy. Specific objectives of this study were to identify the consumer awareness and past experiences regarding organic products, to identify the expectations of consumers if organic products are introduced to the supermarkets in Kandy, and to identify the factors that influence the additional willingness to pay for selected organic vegetables. 


\section{Methodology}

Since the research objective was to identify the market potentials and consumer expectations for organic products in Kandy, three main supermarkets in Kandy, namely, Cargills, Dhanasiri, and Royal Garden Mall were purposely selected. All the customers who came to the above three supermarkets were selected as the sample frame. However, due to time limitations, only thirty customers were randomly selected from each of the supermarkets. Therefore, the final sample comprised of ninety supermarket shoppers who came to buy vegetables from the supermarkets. All these 90 respondents were interviewed during the month of January 2002.

Primary data were collected from these customers by means of a pretested questionnaire. The questionnaire was designed to obtain information on consumer awareness and past experiences about organic products, buying preference of organic products, additional willingness to pay for selected organic vegetables and personal information. In addition, the last question was designed to obtain respondent's comments and suggestions to improve the organic product market. The information regarding the additional willingness to pay was obtained after explaining the benefits of organic product consumption and providing the prevailing price of each type of inorganically produced vegetable.

Descriptive data analysis techniques were adopted to explain the distribution pattern and the relationships among different factors. According to the nature of the variables, quantitative and qualitative data analysis techniques were used to analyze the data. Statistical tests used in the study were binominal test, chisquare tests and regression analysis. Binominal tests were done to test the significance of the categories of one qualitative variable and chi-square tests were done to explain the significance of the overall relationship between two qualitative variables. Factors that influence the additional willingness to pay for selected organic vegetables were determined through regression analysis and the model used for the analysis is given below. Four vegetable types that are highly exposed to pesticides were selected for the study and they were beans, carrots, cabbages and tomato.

\section{The Model}

$$
\begin{aligned}
Y= & \beta_{0}+\beta_{1} X_{1}+\beta_{2} X_{2}+\beta_{3} X_{3} \\
& +\beta_{4} X_{4}+\beta_{5} X_{5}+\beta_{6} X_{6}+\varepsilon
\end{aligned}
$$


- Dependent variable

$\mathrm{Y}=$ Average additional willingness to pay in Rupees

- Independent variables

$\mathrm{X}_{1}=$ Household income in rupees,

$\mathrm{X}_{2}=$ Age in years,

$\mathrm{X}_{3}=$ Years of education,

$\mathrm{X}_{4}=$ Environmental education $(1=$ do have an environmental education and $0=$ do not have an environmental education)

$\mathrm{X}_{5}=$ Family size,

$\mathrm{X}_{6}=$ Number of dependents, and

$\varepsilon=$ Error term.

\section{Results and Discussion}

\section{Consumer awareness about organic products}

Among the respondents, 82 $(91.1 \%)$ had an awareness about organic products while $8(8.9 \%)$ did not have an awareness about organic products. These two groups showed a statistically significant difference. Characteristics of these two groups in terms of age and income are presented in table 1 .
Consumers revealed that personal communications, publications, and mass media were the three approaches by which they came to know about organic products. Among those who had an awareness about organic products, $50 \%$ were made aware through publications. A smaller number of consumers have come to know about organic products through mass media (Table 2). They indicated that the use of mass media in creating an awareness about organic products is very poor in Sri Lanka.

\section{Past organic product consumption experiences}

Among the respondents who have had an awareness about organic products, $73(81.1 \%)$ revealed that they have had past consumption experiences about organic products. There was a significant difference between the group with consumption experience and the group without past consumption experience (Table $3)$. 
Table 1: $\quad$ Sample characteristics

\begin{tabular}{lllllll}
\hline & \multicolumn{3}{c}{ Age (years) } & \multicolumn{3}{c}{ Income (Rs. '000) } \\
\cline { 2 - 7 } & $<40$ & $40-50$ & 750 & $<20$ & $20-40$ & 740 \\
\hline Do have an awareness (82) & 35 & 21 & 26 & 22 & 33 & 27 \\
Do not have an awareness (8) & 3 & 3 & 2 & 4 & & 2 \\
Total (90) & 38 & 24 & 28 & 24 & 37 & 29 \\
\hline
\end{tabular}

Table 2: $\quad$ Sources of Awareness of Organic Products

\begin{tabular}{lc}
\hline Sources & Percentage \\
\hline Publications & 50.0 \\
Personal communization & 35.4 \\
Mass media & 14.6 \\
\hline
\end{tabular}

Table 3: $\quad$ Consumption Experiences by Past Awareness about Organic Products

\begin{tabular}{|c|c|c|c|}
\hline & & $\begin{array}{c}\text { Have } \\
\text { Consumed }\end{array}$ & $\begin{array}{l}\text { Have not } \\
\text { Consumed }\end{array}$ \\
\hline $\begin{array}{l}\text { Do have an awareness } \\
(91.1 \%)\end{array}$ & Percentage & 81.1 & 10.0 \\
\hline $\begin{array}{l}\text { Do not have an awareness } \\
(8.9 \%)\end{array}$ & Percentage & 0.0 & 8.9 \\
\hline
\end{tabular}


The relationship between past awareness and consumption experiences was statistically significant at a probability level of 0.05 . This indicates that awareness programs about organic products could be an effective way of promoting organic products among consumers. Hence, organic product marketers should develop awareness programs aiming supermarket shoppers in order to promote consumer-buying behavior.

A majority of the respondents (58.9\%) have had experiences about consuming organic vegetables. Only $27.4 \%$ of the respondents have consumed organic tea while, $11.0 \%$ consumed organic fruits. Very few respondents have consumed organically produced animal products. Further, a majority of the respondents $(50.7 \%)$ have purchased organic products from retail shops that are selling organic products. A considerable number of respondents have purchased from supermarkets $(28.8 \%)$ and organic farm sites (13.7\%) while a small number of respondents have purchased from vegetables stalls $(4.1 \%)$ and fairs $(2.7 \%)$.

\section{Willingness to buy organic products from supermarkets}

A statistically significant number of respondents (96.3\%) who were aware of organic products revealed that they are willing to buy organic products if organic products are available in the supermarkets. This shows that supermarket shoppers in Kandy expect the availability of organic products. However, only three consumers revealed that they are not willing to buy organic products from supermarkets.

All the respondents who were willing to buy organic products from supermarkets revealed that the main reason to purchase organic products is their health consciousness rather than any other reason such as taste or environmental friendliness. All these respondents revealed that they like to have all types of organic vegetables. Further, a majority revealed that they expect organic fruits $(77.2 \%)$ and organic leafy vegetables (46.8\%) from supermarkets. A considerable number of respondents expect organic animal products (25.3\%), while a comparatively low number of respondents expect to have organic spices (16.5\%) and organic tea (15.2\%). Therefore, organic product marketers could cater to these consumer expectations by introducing organic vegetables and fruits to supermarkets in their introduction process. It will also create a positive image among the consumers for organic products. 


\section{Expected products attributes}

In addition to the selection of organic products, consumers also revealed that they expect more attributes along with the product. Such attributes were indicated to be price, quality, certification, packaging, and shop condition and they are explained below.

\section{Importance Attached to Price}

Of the 79 respondents who were willing to buy organic products from supermarkets, $81 \%$ indicated that price is an important factor in determining their buying behavior. Nine per cent revealed that price is not an important factor while $10 \%$ remained neutral. It shows that a majority of the consumers were not willing to sacrifice the cost for their health advantages. Therefore, the prices of organic products should be competitive with the conventional products. The low percentage of consumers that are neutral about price revealed that marketers should clearly target the consumers with an appropriate price, if not high prices might lead to lower demand.

\section{Importance Attached to Quality}

Respondents indicated that they expect better quality products, as the present organic production processes do not produce products with a good external appearance. Almost all the consumers (99\%) indicated that the quality of the organically produced products should be superior to that of the inorganically produced products, especially in terms of freshness and cleanness. Because of this reason, there should be a continuous supply of fresh vegetables in the supermarkets.

\section{Importance Attached to Packaging}

A majority of the respondents (63\%) indicated that packaging is an unnecessary feature for organic products since it adds an extra cost for the organic product. Further, consumers also indicated that they could not go for the required amount if the products are pre-packed. Some of the respondents (34\%) indicated that they like to have packages for organic products while $3 \%$ remained neutral.

\section{Importance Attached to Certification}

A greater percentage of the respondents $(65 \%)$ who are willing to buy organic products from supermarkets indicated that at least a local institute should certify organic products to assure the quality of products. The others considered that obtaining a certification is a costly 
operation and they were willing to trust the supermarkets for the quality of the organic products.

\section{Importance Attached to Shop Environment}

Accessibility and convenience of purchasing were considered to be important factors. Ninety-four per cent of the consumers indicated that shop environment should be favorable. But, $6 \%$ of the consumers were ready to travel in order to buy organic products. They considered accessibility and convenience neither important nor unimportant for their shopping.

\section{Consumption Preferences}

Respondents indicated different patterns of consumption if the organic products are available to the respondents. Eighty one per cent of the respondents indicated that they would like to consume organic vegetables regularly while $12.7 \%$ of the respondents indicated that they would like to consume organic vegetables occasionally. But, $6.3 \%$ of the respondents indicated that they would like to test before they have a regular consumption pattern.

\section{Additional Willingness to Pay (AWTP) for Selected Organic Vegetables}

Additional willingness to pay values for different organic vegetable types were obtained by indicating the prevailing prices of inorganically produced vegetables in the supermarkets as the base value. Statistically, there was no significant difference between the AWTP values obtained for each vegetable type. Therefore, in general, it could be said that respondents are willing to pay Rs. 12.49 more per $\mathrm{kg}$ of organically produced vegetables than the price of inorganically produced vegetables that are available in the supermarkets (Table 4).

A majority of the respondents (70.9\%) indicated that their AWTP for organic vegetables is more than $10 \%$ of the prices of the vegetables in the supermarkets. But $29.1 \%$ of the respondents indicated that they are willing to pay up to $10 \%$ more than the prices of vegetables in the supermarkets (Table 5). 
Table 4: $\quad$ Summary of Additional Willingness to Pay (AWTP)

\begin{tabular}{lcc}
\hline Vegetable type & $\begin{array}{c}\text { Prevailing } \\
\text { prices of inorganically } \\
\text { produced vegetables (Rs./kg) }\end{array}$ & $\begin{array}{c}\text { AWTP for organically } \\
\text { produced vegetables } \\
\text { (Rs./kg) }\end{array}$ \\
\hline Cabbage & 41.00 & 11.96 \\
Carrot & 71.00 & 13.01 \\
Tomato & 43.00 & 12.08 \\
Beans & 71.00 & 13.10 \\
& & 12.49 \\
\hline
\end{tabular}

Table 5: Distribution of Sample Respondents, by additional willingness to pay for organic vegetables

\begin{tabular}{|c|c|}
\hline $\begin{array}{l}\text { Additional Willingness to } \\
\text { Pay }(\%)\end{array}$ & Percentage \\
\hline$<10$ & 29.1 \\
\hline $10-20$ & 32.9 \\
\hline $20-30$ & 17.7 \\
\hline $30-40$ & 7.6 \\
\hline $40-50$ & 3.8 \\
\hline$>50 \%$ & 8.9 \\
\hline
\end{tabular}

Factors that Influence the Average Additional Willingness to Pay (AAWTP) for Organic Vegetables

Of the different models fitted, lin-lin model gave the best fit with a $R^{2}$ value of 0.3629 (Table 6). It shows that the independent variables explain $36.29 \%$ of the total variation of the AAWTP. Regression analysis results showed that of the six variables considered, income and environmental education were significant at a probability level of 0.05. Therefore, the two null hypotheses, that (i) consumer household income and (ii) environmental education do not influence the average additional willingness to pay for organic vegetables are rejected. Results of the regression analysis revealed 
that an increment of the income by Rs. 1,000 per month would increase the AAWTP for organic vegetables by Rs. 0.0581 compared to the price of inorganically produced vegetables in the supermarkets, while keeping all other factors constant. Further, the positive relationship between the variables AAWTP and the respondent's environmental education revealed that environmental education enhances the AAWTP for organically produced vegetables.
Regression analysis results also showed that the variable years of education was significant at a probability level of 0.01 . Therefore, the null hypothesis, years of education do not influence the average additional willingness to pay for organic vegetables is rejected. This indicates that higher the respondent's formal education, higher the AATWP for organically produced vegetables.

Table 6:

Determinants of AAWTP

\begin{tabular}{lccc}
\hline \multicolumn{1}{c}{ Variable } & Coefficients & $t$ - Ratio & $p$ - Value \\
\hline Intercept & -5.2808 & -0.8261 & 0.411 \\
Income (Rs.'000) & 0.058 & 2.223 & $0.029^{*}$ \\
Age & 0.0235 & 2.961 & 0.768 \\
Years of education & 0.4677 & 1.714 & $0.091^{* *}$ \\
Environmental education & 9.0739 & 4.327 & $0.000^{*}$ \\
Family size & -0.16313 & -0.1781 & 0.859 \\
Number of dependents & 0.4021 & 0.5347 & 0.594 \\
\multicolumn{1}{c}{$R^{2}=0.3629 \quad A d j R^{2}=0.3120$} & $F=7.121$ & $p-$ Value $=0.000$ & $N=82$ \\
\hline
\end{tabular}

Note:

* Significant at 5\% level ** Significant at $10 \%$ level 


\section{Conclusions}

Since this study indicated that consumer awareness effectively advances the demand for organic products, it could be concluded that adoption of proper awareness programs would help in promoting the organic product consumption. Further, given the respondents higher importance attached to price as an important determinant in deciding their buying behavior of organic products, it could be said that the prices of organic products should be competitive with that of the inorganically produced products that are available in the supermarkets. The additional willingness to pay for organic vegetables is shown to be significantly influenced only by the income, environmental education and years of education. Hence it could be concluded that, in general, educational programs would promote the organic product consumption. Similarly along with the price of organically produced products, marketers should also introduce organic products with a good quality that has a certification from a reputed organization. In order to enhance the quality of organic products, establishment of proper local certification standards could be considered important in providing trust among the consumers about organic products.

\section{References}

Agrochemical, (2001). (Online, 2002, Jan). Available: www.foresightpreconception.org.uk/sum maries/frames/agrochem$\underline{\text { nf.html. }}$

Alvares, C., V. Shiva, and S. Ismail (1999). The Organic Farming Reader. India: Other India Press.

Anuradha, H. (2001). Organic Farming, a Growing Trend. Sunday Observer, 14.10.2001: 25.

FAO Statistical Database (2000). (Online, 2002, Jan). Available:

http://apps.fao.org/lim500/ nphwrap.pl?LandUse\&Domai $\underline{\mathrm{n}=\text { Lul } \& \text { Servlet }=1}$

Jayakody, A.N. (2001). Organic Farming in Sri Lanka Past, Present and Future. The Fifth International Foundation of Organic Agriculture Movement (IFORM) - Asia Scientific Conference, 31 Oct. - 4 
Nov. Hangzhow, China, 613.

Kotler, P., (2001). Principals of Marketing. $5^{\text {th }}$ Ed. Irwin, McGraw-Hill, Boston.
Organic Monitor (2001). (Online, 2002, Jan). Available: www.organicmonitor.com 